ISSN : ISSN 2442-4986

An-Nadaa: Jurnal Kesehatan Masyarakat, 7 (2) Desember 2020 :127-131 https://ojs.uniska-bjm.ac.id/index.php/ANN/article/view/3925

\title{
HUBUNGAN KADAR GULA DARAH PENDERITA DIABETES MELLITUS TIPE 2 DENGAN KASUS KEGOYANGAN GIGI PADA PUSKESMAS PENGARON KABUPATEN BANJAR
}

\section{RELATIONSHIP BLOOD SUGAR TYPE 2 DIABETES MELLITUS PATIENTS WITH TEETH ON HEALTH CASE UNSTEADINESS PENGARON BANJAR DISTRICT}

\author{
Anderi Fansurna ${ }^{1 *}$, Naning Kisworo Utami ${ }^{2}$ \\ 1,2Jurusan Keperawatan Gigi Poltekkes Kemenkes Banjarmasin \\ Jl. Garuda No.21A Banjarbaru. Kalimantan Selatan. Indonesia \\ *Email: anderi3arkan@gmail.com
}

\begin{abstract}
One of the health problems of oral health, including dental health. Teeth and mouth can be caused by an abnormal local or systemic diseases, such as diabetes mellitus is a systemic disease, plaque accumulation and modulation of host response through the effects of diabetes can become severe and extensive damage including periodontal dental rocking. The purpose of research to determine the relationship of blood sugar levels of type 2 diabetes mellitus patients with unsteadiness gear case. Type of observational analytic study using a cross sectional study population 359 people, 36 people were taken to sample purposive sampling method. The results of the study by testing Pearson product moment correlation using unknown criteria Sig test was $\mathrm{Ho}=>$ alpha and $\mathrm{Ha}=$ Sig <alpha with alpha $=0.05$ and $a$ value of sig is Sig. (2-tailed) 0.170, (0.170>0.05) can be concluded there is no relationship of blood sugar levels of people with type 2 diabetes mellitus cases unsteadiness teeth using criteria Periodontal Disease Index (PDI), because Sig is greater than alpha. Keep the attention of dental health professionals about the importance of maintaining oral health of patients with diabetes mellitus, checking and controlling blood sugar levels as well as regular dental tartar including cleaning, maintenance for the denture wearer so that the local factors that cause infections of the gums and effects further the cause unsteadiness teeth can be avoided.
\end{abstract}

Keywords : Blood sugar; Teeth unsteadiness

\begin{abstract}
ABSTRAK
Masalah kesehatan salah satunya kesehatan rongga mulut termasuk kesehatan gigi. Gigi dan mulut dapat mengalami kelainan akibat suatu penyakit lokal maupun sistemik, antara lain penyakit sistemik adalah diabetes mellitus, akumulasi plak dan modulasi dari respon host melalui efek dari diabetes dapat berubah menjadi severe dan terjadi kerusakan periodontal yang luas termasuk gigi goyang. Tujuan penelitian untuk mengetahui hubungan kadar gula darah penderita diabetes mellitus tipe 2 dengan kasus kegoyangan gigi. Jenis penelitian bersifat analitik observasional dengan rancangan cross sectional, populasi penelitian 359 orang, sampel 36 orang diambil dengan metode purposive sampling. Hasil penelitian dengan uji korelasi menggunakan produk moment pearson diketahui kriteria pengujian adalah $\mathrm{Ho}=\mathrm{Sig}>\mathrm{alpha}$ dan $\mathrm{Ha}=$ Sig<alpha dengan nilai alpha $=0,05$ dan nilai sig yaitu Sig. (2-tailed) 0,170, $(0,170>0,05)$ dapat diambil kesimpulan tidak ada hubungan kadar gula darah penderita diabetes mellitus tipe 2 dengan kasus kegoyangan gigi dengan menggunakan kriteria Periodontal Disease Indeks (PDI), karena Sig lebih besar dari alpha. Perlu perhatian dari tenaga kesehatan gigi tentang pentingnya menjaga kesehatan gigi dan mulut penderita diabetes mellitus, pemeriksaan dan pengontrolan kadar gula darah serta kesehatan gigi secara berkala termasuk pembersihan karang gigi, pemeliharaan bagi pemakai gigi tiruan sehingga faktor lokal yang menjadi penyebab terjadinya infeksi pada gusi dan efek lanjut penyebab kegoyangan gigi dapat dihindari.
\end{abstract}

Kata kunci : Kadar gula darah; Kegoyangan gigi 


\section{PENDAHULUAN}

Salah satu masalah kesehatan yaitu masalah kesehatan rongga mulut termasuk kesehatan gigi. Seperti organ tubuh lainnya maka gigi dan mulut juga mengalami kelainan akibat suatu penyakit lokal maupun sistemik, yang salah satu penyakit sistemik adalah diabetes mellitus. Diabetes mellitus (DM) atau kencing manis adalah suatu kumpulan gejala yang timbul pada seseorang karena adanya peningkatan kadar gula dalam darah akibat kekurangan insulin. Diabetes melitus kini menjadi ancaman yang serius bagi manusia dan telah menjadi penyebab kematian urutan ketujuh di dunia (1).

Diabetes mellitus (DM) tipe 2 merupakan jenis diabetes yang paling umum terjadi, dengan prevalensi sekitar 85-90\%. Tahun 2003, World Health Organization (WHO) memperkirakan 194 juta atau 5,1\% dari 3,8 milyar penduduk Indonesia usia 20-79 tahun menderita DM dan tahun 2025 meningkat menjadi 333 juta (2). Diabetes merupakan kondisi sistemik yang dapat meningkatkan keparahan dan perluasan dari penyakit periodontal pada pasien yang terkena. Diabetes tipe 2 seringkali berkembang pada populasi dewasa pada saat yang bersamaan dengan periodontitis kronis (3). Efek yang sinergis dari akumulasi plak dan modulasi dari respon host yang efektif melalui efek dari diabetes yang dapat berubah menjadi severe dan terjadi kerusakan periodontal yang luas termasuk gigi goyang yang dapat mempersulit perawatan dengan teknik klinis standar mengontrol kondisi sistemik (4).

Oliver dan Ternoven menyimpulkan bahwapernyataan diabetes menambah risiko terjad inya penyakit periodontal terlalu dilebih-lebihkan. Sedangkan Loe tahun 1993, menyatakan bahwa penyakit periodontal merupakan komplikasi ke enam dari penyakit diabetes mellitus (5). Pada tahun tahun 1970 telah diperoleh kesimpulan bahwa skor penyakit gingival dan periodontal lebih tinggi secara signifikan pada pasien diabetes dibandingkan nondiabetik, yang mana hal ini didapat dari laporan hasil penelitian longitudinal selama dua tahun (6).

Jumlah penderita diabetes mellitus tipe 2 yang melakukan pemeriksaan kesehatan gigi dan mulut di Puskesmas Pengaron dengan keluhan utama kegoyangan gigi cukup tinggi, menempati urutan kedua setelah kasus peradangan gusi (gingivitis) (Laporan tahunan Puskesmas Pengaron). Tujuan penelitian ini untuk mengetahui hubungan kadar gula darah penderita diabetes mellitus tipe 2 dengan kasus kegoyangan gigi pada Puskesmas Pengaron, kabupaten Banjar.

\section{BAHAN DAN METODE}

Jenis penelitian ini adalah penelitian analitik observasional dengan menggunakan rancangan penelitian cross sectional dimana variabel pada objek penelitian di ukur atau dikumpulkan secara simultan (dalam waktu yang bersamaan) (7). Populasi penelitian adalah seluruh pasien diabetes mellitus tipe 2 yang berkunjung ke Puskesmas Pengaron, kabupaten Banjar. Sampel penelitian adalah penderita diabetes mellitus tipe 2 yang berkunjung ke Puskesmas Pengaron, kabupaten Banjar, diambil dengan metode purposive sampling yaitu sampel yang anggota sampelnya dipilih secara sengaja atas dasar pengetahuan dan keyakinan peneliti (8). Besarnya sampel diambil 36 orang yang memenuhi kriteria sampel, yang secara umum untuk penelitian korelasional jumlah sampel (n) sebanyak 30 individu/ orang telah dipandang cukup besar (8). Kriteria sampel: Penderita diabetes mellitus tipe 2, berumur 20 tahun atau lebih, memiliki gigi indeks. Gambaran statistik meliputi rata-rata, standar deviasi, jumlah dan persentase digunakan untuk menjelaskan status jaringan periodontal dan tingkat derajat kegoyangan gigi. Perbandingan hubungan antara penderita diabetes mellitus tipe 2 dengan kasus kegoyangan gigi dan yang tidak mengalami kegoyangan gigi dilakukan uji statistik dengan uji korelasi menggunakan Produk Moment pearson.

\section{HASIL DAN PEMBAHASAN}

\section{Analisis Univariat}

Tabel 1. Distribusi Frekuensi Penderita Diabetes Mellitus Tipe 2 Berdasarkan Jenis Kelamin, Umur, Kadar gula darah sewaktu (Ratarata 3 kunjungan terakhir) pada Puskesmas Pengaron 


\begin{tabular}{lcc}
\hline \multicolumn{1}{c}{ Variabel } & n & $\%$ \\
\hline Jenis Kelamin & 15 & 41,7 \\
Laki-laki & 21 & 58,3 \\
$\begin{array}{l}\text { Perempuan } \\
\text { Umur }\end{array}$ & & \\
20-40 tahun & 8 & 22,2 \\
$41-60$ tahun & 19 & 52,8 \\
$>60$ tahun & 9 & 25,0 \\
Kadar GulaDarah Sewaktu & & \\
(Rata-rata 3 kunjungan terakhir) & & \\
$<200$ mg/dL & 2 & 5,55 \\
$\geq 200$ mg/dL & 34 & 94,45 \\
Jumlah & 36 & 100,0 \\
\hline
\end{tabular}

Berdasarkan tabel 1. Diketahui subjek penelitian penderita diabetes mellitus tipe 2 berjumlah 36 orang dan mayoritas subjek penelitian adalah perempuan yaitu 21 orang (58,3\%) sedangkan lakilaki yaitu 15 orang $(41,7 \%)$. Berdasatrkan variabel umur, diketahui rentang umur subjek penelitian penderita diabetes mellitus tipe 2 yang terbanyak adalah rentang umur 41-60 tahun yaitu 19 orang $(52,8 \%)$, kemudian rentang umur $>60$ tahun berjumlah 9 orang $(25,0 \%)$ dan yang paling sedikit rentang umur 20-40 tahun yaitu 8 orang (22,2\%).Berdasarkan kadar gula sewaktu, diketahui rentang Kadar Gula Darah Sewaktu rata-rata 3 kunjungan terakhir subjek penelitian penderita diabetes mellitus tipe 2 yang terbanyak adalah $\geq 200$ $\mathrm{mg} / \mathrm{dL}$ berjumlah 34 orang $(94,45 \%)$ kemudian $<200$ $\mathrm{mg} / \mathrm{dL}$ berjumlah 2 orang $(5,55 \%)$.

Tabel 2. Kriteria Periodontal Disease Indeks (PDI) Pada Penderita Diabetes Mellitus Tipe 2

\begin{tabular}{lccccc}
\hline Kriteria & n & Min & Max & Mean & $\begin{array}{c}\text { Std. } \\
\text { Deviasi }\end{array}$ \\
\hline $\begin{array}{l}\text { PDI } \\
(0,0-6,0)\end{array}$ & 36 & 1,00 & 4,40 & 3,3431 & .71679 \\
\hline Valid n & 36 & & & & \\
\hline
\end{tabular}

Berdasarkan tabel 2. diketahui kriteria minimum Periodontal Disease Indeks (PDI) pada penderita diabetes mellitus tipe 2 adalah 1,00 dan maximum 4,40 sehingga didapat mean 3,3431 .

\section{Analisis Bivariat}

Tabel 3. Korelasi Kriteria Periodontal Disease Indeks (PDI) Dengan Kadar Gula Darah Sewaktu Rata-Rata 3

Kunjungan Terakhir Penderita Diabetes Mellitus Tipe 2

\begin{tabular}{llcc}
\hline & & Kriteria PDI (0,0 - 6,0) & $\begin{array}{c}\text { GDS rata-rata 3 kunjungan } \\
\text { terakhir }\end{array}$ \\
\hline Kriteria PDI (0,0 - 6,0) & Pearson Correlation & 1 & .234 \\
& Sig. (2-tailed) & 36 & .170 \\
& $\mathrm{~N}$ & .234 & 36 \\
GDS rata-rata 3 & Pearson Correlation & & 1 \\
kunjungan terakhir & Sig. (2-tailed) & .170 & 36 \\
\hline & $\mathrm{N}$ & 36 & \\
\hline
\end{tabular}

Uji korelasi antara Kriteria Periodontal Disease Indeks (PDI) dengan Kadar Gula Darah Sewaktu rata-rata 3 kunjungan terakhir penderita diabetes mellitus tipe 2 dilakukan pengujian dengan menggunakan Produk Moment pearson.

Berdasarkan tabel 3 dapat diketahui kriteria pengujian adalah $\mathrm{Ho}=\mathrm{Sig}>\mathrm{alpha}$ dan $\mathrm{Ha}=\mathrm{Sig}<\mathrm{alpha}$ dengan nilai Alpha $=0,05$. Nilai sig di ambil dalam tabel yaitu Sig. (2-tailed) dengan nilai 0,170, 0,170>0,05 (Sig>alpha) sehingga Ho diterima, dapat diambil kesimpulan tidak ada hubungan kadar gula darah penderita diabetes mellitus tipe 2 dengan kasus kegoyangan gigi dengan menggunakan kriteria Periodontal Disease Indeks (PDI), karena Sig lebih besar dari alpha.

\section{PEMBAHASAN}

Terdapat teori yang menyebutkan bahwa diabetes mellitus yang disertai oleh beberapa 
berperan dalam terjadinya periodontitis kronis yang mengakibatkan gigi menjadi goyang (9). Hasil penelitian ini berbeda dengan teori tersebut karena penyebab gigi goyang tidak hanya faktor sistemik saja, ada faktor lain yang mengikuti. Penyebab gigi goyang pada orang dewasa selain faktor sistemik (diabetes mellitus yang tidak terkontrol) terdapat faktor lokal yaitu subgingival kalkulus dan trauma (10).

Walaupun faktor-faktor lain dapat mempengaruhi jaringan periodontal, penyebab utama penyakit periodontal adalah mikroorganisme yang berkumpul dipermukaan gigi (plak bakteri dan produk-produk yang dihasilkannya) dan membentuk koloni, beberapa kelainan sistemik dapat berpengaruh buruk terhadap jaringan periodontal, tetapi faktor sistemik semata tanpa adanya plak bakteri tidak dapat menjadi pemicu terjadinya periodontitis (11).

Hasil penelitian ini berbeda karena pada subjek penelitian yang dilakukan pemeriksaan telah banyak kehilangan gigi tetapi masih terdapat gigi indeks untuk pemeriksaan Periodontal Disease Indeks (PDI), dan juga adanya sebagian subjek penelitian yang menggunakan gigi tiruan sehingga nilai ratarata yang didapat untuk melihat kegoyangan gigi dengan kriteria Periodontal Disease Indeks (PDI) diperoleh angka mean 3,3431 , nilai dimana termasuk gingivitis berat tetapi belum menyebabkan kegoyangan gigi dan belum terjadinya kehilangan perlekatan serat periodontal atau loss of attachment (12). Gingivitis berat ini bila tidak cepat diatasi akan berlanjut menjadi lebih parah, meluas dari gusi kearah tulang dibawah gigi sehingga menyebabkan kerusakan yang lebih luas pada jaringan periodontal (13).

Hasil ini nantinya akan berpengaruh pada tingkat pengetahuan penderita diabetes mellitus yang akan mempengaruhi perilaku penderita diabetes mellitus dalam menjaga kesehatan gigi dan mulutnya. Pengetahuan penderita tentang diabetes mellitus merupakan sarana yang dapat membantu penderita menjalankan penanganan diabetes sehingga semakin banyak dan semakin baik penderita mengerti tentang penyakitnya, semakin mengerti bagaimana harus mengubah perilakunya dan mengapa hal itu diperlukan (14).

Upaya yang perlu dilakukan adalah adanya perhatian dari tenaga kesehatan gigi tentang pentingnya menjaga kesehatan gigi dan mulut bagi penderita diabetes mellitus, pemeriksaan dan pengontrolan kesehatan gigi secara berkala termasuk melakukan pembersihan karang gigi serta pemeliharaan bagi pemakai gigi tiruan sehingga faktor lokal yang menjadi penyebab terjadinya infeksi pada gusi (gingivitis) dan efek lanjut yang menyebabkan kegoyangan gigi dapat dihindari, serta pentingnya diberikan pengetahuan untuk selalu melakukan pengontrolan kadar gula darahnya secara teratur (15).

\section{KESIMPULAN DAN SARAN}

Berdasarkan hasil penelitian tentang hubungan kadar gula darah penderita diabetes mellitus tipe 2 dengan kasus kegoyangan gigi pada pasien rawat jalan Puskesmas Pengaron kabupaten Banjar dapat disimpulkan bahwa Kadar Gula Darah Sewaktu rata-rata 3 kunjungan terakhir subjek penelitian penderita diabetes mellitus tipe 2 mayoritas adalah $\geq 200 \mathrm{mg} / \mathrm{dL}(94,45 \%)$, Kasus kegoyangan gigi subjek penelitian penderita diabetes mellitus tipe 2 dengan melihat menggunakan kriteria Periodontal Disease Indeks didapat mean 3,3431, yaitu nilai ratarata dimana belum terlihat adanya kegoyangan gigi, Tidak ada hubungan kadar gula darah penderita diabetes mellitus tipe 2 dengan kasus kegoyangan gigi dengan menggunakan kriteria Periodontal Disease Indeks (PDI).

Saran bagi penderita diabetes mellitus diberikan pengetahuan tentang pentingnya untuk selalu melakukan pengontrolan kadar gula darahnya secara teratur dan petugas kesehatan gigi agar lebih meningkatkan dalam memberikan penyuluhan kepada penderita diabetes mellitus tentang pentingnya menjaga kesehatan gigi dan mulut. Perlu adanya penelitian lanjutan dengan melihat faktor lain seperti seperti faktor lokal penyebab kegoyangan gigi, pengetahuan penderita diabetes mellitus, dan lain-lain serta diharapkan untuk dapat menambah sampel penelitian sehingga menjadi lebih heterogen dan representatiif.

\section{UCAPAN TERIMAKASIH}

Ucapan terimakasih kepada semua rekan dan pihak yang tidak dapat penulis sebutkan satu persatu yang turut membantu dalam penelitian ini. Pihak Puskesmas Pengaron, kabupaten Banjar yang telah memberi ijin untuk tempat penelitian dan 
seluruh keluarga tercinta yang telah banyak memberikan dukungan baik moril maupun materiil.

\section{DAFTAR PUSTAKA}

1. Anggoro, M. Toha. Metode Penelitian Edisi 2. Jakarta: Universitas Terbuka; 2007.

2. Ayu Md Lely S, dan Indirawati T, Pengaruh Kadar Glukosa Darah Yang Terkontrol Terhadap Penurunan Derajat Kegoyangan Gigi Penderita Diabetes Mellitus, KTI, 2003.

3. Carpenito, Lynda Juall. Buku Saku Diagnosa Keperawatan (Handbook of Nursing Diagnosis) Edisi 8, Jakarta: Penerbit Buku Kedokteran EGC; 1999.

4. Forum Diagnosticum, Peran HbA1c Dalam Skrining Dan Diagnosis Diabetes, Page 9 of 18, 2010.

5. Notoatmodjo. S Metodologi Penelitian Kesehatan. Jakarta: Rineka Cipta; 2005.

6. Notoatmodjo. S Metodologi Penelitian Kesehatan. Jakarta: Rineka Cipta; 2010.

7. Kurniawan I, Diabetes mellitus tipe 2 pada usia lanjut, Majalah Kedokteran Indonesia, Volum:60, Nomor:12. Indonesia. Digital journals; 2010.

8. Muchlis M R. Hubungan Periodontitis Dengan Diabetes Mellitus Serta Perawatannya. KTI; 2010.

9. Nathan David M., Delahanty Linda M. Menaklukkan Diabetes. Jakarta: PT. Bhuana Ilmu Populer; 2009.

10. Putro PJS, Suprihatin. Pola diet tepat jumlah, jadwal, dan jenis terhadap kadar gula darah pasien diabetes mellitus tipe 2, Jurnal STIKES volume 5, No.1; 2012.

11. Rahmadilanti N, Muhlisin A,.. Hubungan Antara Pengetahuan Tentang Penyakit Dan Komplikasi Pada Penderita Diabetes Mellitus Dengan Tindakan Mengontrol Kadar Gula Darah. Publikasi ilmiah.ums.ac.id; 2010.

12. Lestari, C.A., Widiantara, T., Hasnelly. Pengaruh Substitusi Tepung Kacang Koro Pedang (Canavalia ensiformis) Terhadap Karakteristik Roti Tawar. Jurnal Penelitian Tugas Akhir. 2016.

13. Maida, D.C., Widodo, Adhani, R. Hubungan Tingkat Pengetahuan Menyikat Gigi Dengan Indeks Gingiva Siswa Madrasah Tsanawiyah. Dentino Jurnal Kedokteran Gigi. 2017, Vol. I (1).

14. Sugiarti, T., Santik, Y.D.P. Kejadian Periodontitis Di Kabupaten Magelang. Higeia Journal Of Public Health Research And Development. 2017, Vol. 1 (4).
15. Wilis, RR.S.S.S.S., Sudirman, P.L., Sawitri, AA.S. Kebutuhan Perawatan Periodontal Pada Remaja Usia 15-18 Tahun di SMAN Semarapura, Klungkung. Bali Dental Journal (BDJ). 2017, Vol. 1 (2). 